\title{
Effect of hoof trimmer intervention in moderately lame cows on lameness progression and milk yield
}

\author{
A. García-Muñoz, ${ }^{*}$ N. Singh,† C. Leonardi,ł and N. Silva-del-Ríoß\# ${ }^{1}$ \\ *Grupo Fisiopatología de la Reproducción, Dpto. PASACTA Facultad de Veterinaria, Universidad CEU Cardenal Herrera, Valencia, Spain 46115 \\ †Guru Angad Dev Veterinary and Animal Sciences University, Ludhiana, India 141004 \\ łBehavioral and Community Health Sciences, School of Public Health, Louisiana State University Health Sciences Center, New Orleans 70112 \\ §Veterinary Medicine Teaching and Research Center, 18830 Road 112, Tulare, CA 93274 \\ \#Department of Population Health and Reproduction, School of Veterinary Medicine, University of California, Davis 95616
}

\section{ABSTRACT}

The objective of this study was to evaluate the effect of hoof trimmer intervention (HTI) in moderately lame cows on lameness progression and milk yield. Two freestall Holstein herds were enrolled. Cows were milked 2 (herd A: 2,374 cows) or 3 (herd B: 2,800 cows) times a day. Within each dairy, moderately lame cows [locomotion score $(\mathrm{LS})=3$ on a 5 -point scale] were randomly assigned to control group $(\mathrm{CON}$; herd $\mathrm{A}=$ 66 , herd $\mathrm{B}=84$ ) or treatment group (HTI; evaluated and treated by the hoof trimmer under researchers' supervision; herd $\mathrm{A}=73$; herd $\mathrm{B}=75$ ). Enrollment criteria were $<350 \mathrm{~d}$ in milk, $<180 \mathrm{~d}$ pregnant, $>10 \mathrm{~kg} / \mathrm{d}$ of milk yield, not selected for therapeutic trimming 2 mo before enrollment, and $>14$ observations of daily milk yield during the study period. Biweekly lameness scoring (LS $\leq 2, \mathrm{LS}=3, \mathrm{LS} \geq 4$ ) was conducted up to 6 wk post-intervention. Lesion type and severity records were collected at intervention from HTI cows and up to 6 wk post-intervention from all enrolled cows identified as lame by farm employees. Daily milk yield data were collected from -1 to 6 wk relative to intervention using Afifarm (Afimilk Ltd., Kibbutz Afikim, Israel) records. No treatment effect was detected on the predicted probability of locomotion score, but the predicted probability of LS $\geq 3$ decreased over time in herd $\mathrm{B}$, whereas in herd $\mathrm{A}$, it initially decreased but later increased. A tendency for a treatment by time interaction was observed in herd $\mathrm{A}$; at 2 wk post-intervention, the predicted probability for LS $\geq 3$ was higher for HTI (0.69) than for CON (0.43), but similar at $4 \mathrm{wk}(0.41$ HTI, $0.49 \mathrm{CON})$ and $6 \mathrm{wk}(0.77 \mathrm{HTI}, 0.73 \mathrm{CON})$. At intervention, most study cows had no lesions (41.2\%),

Received December 13, 2016.

Accepted July 25, 2017.

${ }^{1}$ Corresponding author: nsilvadelrio@ucdavis.edu sole hemorrhages $(28.4 \%)$, thin soles $(8.8 \%)$, or vertical fissure $(6.8 \%)$. During the $6 \mathrm{wk}$ following intervention, a similar proportion of cows were identified as lame in CON $(8.7 \%)$ and HTI (6.7\%) groups. In herd A, milk yield (least squares means \pm standard error) was similar for CON $(42.0 \pm 0.77 \mathrm{~kg} / \mathrm{d})$ and HTI $(42.3 \pm 0.75$ $\mathrm{kg} / \mathrm{d}$ ) cows, whereas in herd $\mathrm{B}$, it tended to be lower for HTI $(43.7 \pm 0.61 \mathrm{~kg} / \mathrm{d})$ than for CON $(45.2 \pm 0.59$ $\mathrm{kg} / \mathrm{d}$ ) cows. A significant effect of time was detected on both dairies, with milk yield decreasing over the study period. In our study, implementing HTI on moderately lame cows resulted in no improvement in gait or milk yield. The low presence of severe lesions amenable to therapy may partially explain our findings.

Key words: hoof trimmer, lameness, milk yield

\section{INTRODUCTION}

For decades, lameness has been a major challenge for the dairy industry. Its prevalence remains unacceptably high worldwide: $33 \%$ in Chile (Tadich et al., 2010), $28 \%$ in Austria (Kofler et al., 2013), and 37\% in the United Kingdom (Barker et al., 2010). In North America, von Keyserlingk et al. (2012) reported an average lameness of $55 \%$ in northeast US herds and $30 \%$ in both British Columbia (Canada) and California herds. Lameness has been associated with reproductive failure (Garbarino et al., 2004), an increase of involuntary culling rates (Shearer et al., 2013), and a decrease in milk production (Juarez et al., 2003; Archer et al., 2010; Reader et al., 2011). Moreover, clinical and subclinical lameness has been associated with pain and discomfort (Juarez et al., 2003; Dyer et al., 2007). Lameness is considered the most representative animal-based indicator of welfare on dairies (Whay and Shearer, 2017).

In a recent review, Huxley (2013) suggested that 2 approaches were necessary to reduce lameness prevalence on dairies: (1) early identification and prompt treatment of clinical cases, and (2) implementation of farm-specific strategies to prevent lameness. Several 
studies have investigated the effects of early lameness treatment on lameness progression or milk production (Leach et al., 2012; Gundelach et al., 2013; Groenevelt et al., 2014; Thomas et al., 2015). On 4 UK dairies, Leach et al. (2012) showed that early lameness treatment resulted in a higher proportion of sound cows at 4 wk, but no differences were detected at 6 or 10 wk. In a follow-up study carried out over 3 consecutive years in 4 UK dairies, early therapeutic trimming improved locomotion score (LS) during years 2 and 3 but not in year 1 (Groenevelt et al., 2014). On a 144-cow dairy farm in Germany, early lameness treatment did not lead to a firm conclusion on an LS decrease during a 41-wk period (Gundelach et al., 2013). Two recent studies compared 4 treatments for lameness (Thomas et al., 2015, 2016), including therapeutic trimming alone or therapeutic trimming combined with a nonsteroidal anti-inflammatory drug (NSAID), a foot block, or both. In both studies, only cows with visible lesions were enrolled. Treatment of acutely lame cows with therapeutic trimming, an NSAID, and a foot block increased the proportion of sound cows (score 0; 0 to 3 scale) at $35 \mathrm{~d}$, but no differences were detected in the proportion of nonlame cows (scores 0 and 1; Thomas et al., 2015). However, delaying lame cow treatment by $>2$ wk resulted in a lack of treatment effect on lameness progression (Thomas et al., 2016).

Visual observation of gait and posture abnormalities is the most common method to identify lame cows that need to be treated. The 5-level LS system described by Sprecher et al. (1997) is widely referred to in the literature (Potterton et al., 2012). However, its implementation is a time-consuming task that requires individual observation of cows while they are walking and standing. Research studies conducted in Midwest US herds (Espejo et al., 2006) and UK herds (Horseman et al., 2014) revealed that farmers often underestimate mild lameness cases. Similarly, in California dairies, lameness identification and treatment is mostly reserved for severe cases with LS >3 (Pineda et al., 2015).

Because prior studies (Leach et al., 2012; Thomas et al., 2015) suggested that early lameness treatment may improve lameness progression, we hypothesized that treatment of moderately lame cows in large California herds would improve gait and milk yield of cows. To test this hypothesis, we evaluated the effect of hooftrimming treatment of moderately lame cows on lameness progression and milk yield.

\section{MATERIALS AND METHODS}

All procedures were approved by the University of California Davis Institutional Animal Care and Use Committee (\# 17440).

\section{Cows and Herd Management}

The study was conducted on 2 commercial Holstein dairy farms (A and B) in Tulare County (California) between March and May 2014. Herds were selected based on their proximity (1 mile apart), ability to electronically collect daily milk yield data (Afimilk Ltd., Kibbutz Afikim, Israel), ability to automatically sort cows after milking, and willingness to cooperate with University of California-Davis researchers.

Herd A housed 2,374 Holstein milking cows in dry manure-bedded freestall facilities. Cows were milked 2 times a day in 2 herringbone parlors with double-20 stalls. Herd average ECM yield at 305 d was 11,067 $\mathrm{kg} /$ cow. Herd B housed 2,800 Holstein milking cows in sand-bedded freestall facilities. Cows were milked on a 72-stall rotary parlor 3 times a day. Herd average ECM yield at $305 \mathrm{~d}$ was $13,200 \mathrm{~kg} / \mathrm{cow}$. On both dairies, lactating cows were fed a TMR 2 times a day. Facilities had grooved concrete floor alleys that were flushed with lagoon water for manure removal 3 times a day. Rubber mats covered feed alleys and parlor walkways. In freestalls, cooling was achieved by soaking and forced ventilation. Both herds used forced ventilation in the milking parlor; herd B also used soakers and fans in the holding area.

On both dairies, foot baths were rectangular structures, $258 \mathrm{~cm}$ long and $190 \mathrm{~cm}$ wide. Foot baths were cleaned and refilled with new disinfectant solution after each milking shift. Disinfectant products used were $5 \%$ formalin (35\% formaldehyde) or $5 \%$ copper sulfate solution. The same external hoof trimming service performed preventive and therapeutic trimming on herd A (Tuesday and Thursday) and herd B (Monday). On both dairies, the hoof trimmers started their work at $0630 \mathrm{~h}$ to avoid exposing cows to high summer temperatures while waiting to be treated. Lameness detection was performed by dairy employees mainly when cows were moved to the milking parlor and during milking by observation of uneven gait or claudication. Although lame cows were identified and noted daily, the search for lame cows intensified on the day before the scheduled hoof trimmer visit. After each treatment, the hoof trimmer recorded the cow identity, the type of lesion and its location, and the type of intervention performed. Both herds entered these records in their farm dairy management software (DairyComp 305; Valley Agricultural Software Inc., Tulare, CA).

\section{Study Design}

A longitudinal study was designed to evaluate hoof trimmer intervention in moderately lame cows on milk yield and lameness progression. In an earlier study, 
Leach et al. (2012) observed that at 4 wk post-intervention, the proportion of cows with LS $<2$ (on a 1 to 3 scale) was $38 \%$ for cows that received early therapeutic treatment versus $18 \%$ for control cows. Based on this difference, sample-size calculations were conducted: a sample of 78 cows per group would be required to detect a $20 \%$ difference at the $5 \%$ significance level with $80 \%$ power. A secondary outcome was milk yield. Data from Akin and Silva-del-Rio (2013) showed a $3 \mathrm{~kg} / \mathrm{d}$ difference in milk yield between cows with LS 1 and LS 3. A sample size of 139 cows per group would be required to detect a $3-\mathrm{kg}$ difference in milk yield at the $5 \%$ significance level with $80 \%$ power, using $9.5 \mathrm{~kg} / \mathrm{d}$ as the standard deviation.

Based on a single time observation, cows were locomotion scored by 2 experienced veterinarians (AGM and NS) according to the 5-point scale of Sprecher et al. (1997). To minimize intra- and interobserver disagreement, both observers reviewed online materials (Zinpro Corp., 2010; Washington State University, 2013) and performed practice rounds on dairies. When researchers disagreed on scores, cows were noted and re-evaluated later. An extensive description of training and interobserver agreement evaluation for locomotion scoring in the present study is described elsewhere (García-Muñoz et al., 2016).

Locomotion score evaluations were performed over 2 consecutive days, 2 to $3 \mathrm{~d}$ before intervention. In herd A, cows were evaluated as they exited the milking parlor. The evaluation was done while cows were walking through a narrow, flat sorting lane with a grooved concrete floor. In herd B, complete evaluation of lactating cows was not possible due to the fast flow of cows exiting the rotary parlor. Thus, only cows with LS $\geq 3$ were identified and recorded when walking back to their pens on a flat, grooved concrete floor. Based on a single observation, 187 and 282 cows with LS 3 were identified in herd $\mathrm{A}$ and herd $\mathrm{B}$, respectively. Cows with $>350$ DIM $(\mathrm{n}=43),>180 \mathrm{~d}$ pregnant $(\mathrm{n}=10)$, producing $<10 \mathrm{~kg} / \mathrm{d}$ of milk $(\mathrm{n}=2)$, selected for therapeutic trimming 2 mo before study onset $(\mathrm{n}=112)$, or with $<14$ observations of daily milk yield during study period (n $=4$ ) were removed from the final data set. Cow-level information on lactation number and DIM was extracted from the DairyComp 305 database (Valley Agricultural Software Inc.). Cows were randomly assigned to the treatment or control group using the RAND function in Excel (2010; Microsoft Corp., Redmond, WA). In total, 150 cows were assigned to the control group $(\mathbf{C O N}$; no intervention; herd $\mathrm{A}=66$, herd $\mathrm{B}=84$ ) and 148 to the treatment group (HTI, hoof trimmer intervention; the 4 feet were evaluated and treated by the hoof trimmer under researchers' supervision; herd $\mathrm{A}=73$; herd $\mathrm{B}=$ $75)$.
Before the intervention, hoof trimmers met with researchers to be refreshed on therapeutic trimming techniques based on the 5-step method described by Toussaint-Raven (1985). The day before the trimming intervention, dairy producers and managers were given the list of cows assigned to HTI. In herd A, the manager and his assistant moved cows to a lame cow holding pen during the night milking shift (2000 to $0400 \mathrm{~h}$ ) to be ready for the hoof trimmer the next day. In herd B, cows were moved to a treatment pen using sorting gates as soon as they left the milking parlor. Cows stayed in the treatment pen for less than $2 \mathrm{~h}$. Hoof trimmer intervention was performed on 2 consecutive days in herd A to facilitate cow sorting, and on a single day in herd B. No intervention was performed on CON cows; they just followed the routine dairy management.

All treatments were performed under researchers' supervision. Hoof lesion type and lesion severity were recorded at intervention (HTI cows) and from cows identified as lame (CON and HTI) by farm employees during the 6 wk following intervention. Diagnosis of thin soles was based on sole horn flexibility after thumb pressure or toe length $<7.5 \mathrm{~mm}$ from coronary band (van Amstel et al., 2002; Archer et al., 2015). Other lesions were recorded following definitions of the ICAR Claw Health Atlas (ICAR Working Group, 2015). Lesion severity was scored using a modified abc lesion scoring system described by Burgi and Cook (2006) that classified lesions into 3 scores $(1=$ mild, $2=$ moderate, $3=$ severe). The affected claw was recorded. Cows on HTI received a functional trim in all 4 feet. If lesions were visible, a therapeutic trimming was performed following the Dutch technique (Toussaint-Raven, 1985). According to lesion type and severity, trimmers performed the required intervention. Infectious lesions such digital dermatitis and interdigital necrobacillosis (foot rot) were treated with topical tetracycline. When noninfectious lesions such as sole ulcers and white line disease were detected, claw horn was removed to drain abscesses, to eliminate necrotic tissues, or to remove pressure from the corium. For noninfectious lesions of severity 1, the claw-bearing surface was rebalanced, lowering the surface of the affected claw. For lesions of severity 2 and 3 , a wooden block was placed on the sound claw to elevate the affected claw. No NSAID were used during HTI. When more than one injury was detected, the most severe one was chosen to classify the cow.

After intervention, lame cow identification and treatment followed standard herd protocol practices. On the day of treatment of HTI cattle, farm personnel routinely performing lame cow identification were not involved in cow segregation, thus, they were blinded to treatments. For 6 consecutive weeks, researchers (AGM and NS) visited herds during their scheduled therapeu- 
tic trimming. All enrolled cows selected for treatment by farm personnel were evaluated, and the type and severity of lesion was recorded. Three LS evaluations were performed every other week after intervention. On both dairies, researchers were given access to the sorting gate system to separate enrolled cows for LS evaluations.

Daily milk yield data were collected from the Afifarm management software (Afimilk Ltd.) from -7 to $42 \mathrm{~d}$ relative to intervention day. Before data analysis, milk yield data were screened and observations outside the cow's mean \pm 2.33 standard deviations were not included in the analysis. These outliers were most likely caused by errors with the radiofrequency identification (RFID) system, with milk weight values being attributed to the wrong cow ID.

\section{Statistical Analysis}

Data were analyzed using SAS/STAT software (SAS 9.2; SAS Institute Inc., Cary, NC). Lactation number, DIM, days pregnant, and average daily milk yield registered 1 wk before treatment application were compared between treatments using the MIXED procedure, with treatment as the only fixed effect in the model. Although treatment was consistent between the 2 dairies because it was performed by the same trimmer, cow management before and after trimming was different. Therefore, treatment by dairy interaction as a fixed effect on milk yield was investigated within the first week post-intervention. The interaction between treatment and dairy tended toward significance $(P=0.067)$; thus, probability of lameness and milk yield were analyzed separately for herd A and herd B.

Locomotion was scored on 5-level ordinal scale; however, for statistical analysis, observations were grouped into 3 categories (LS $\leq 2, \mathrm{LS}=3, \mathrm{LS} \geq 4$ ) using the GLIMMIX procedure with multinomial distribution, the cumulative logit, and the Laplace estimation method (Littell et al., 2006). Predictive probabilities of each response category were estimated using the ESTIMATE statement and ILINK option as described in Gbur et al. (2012). The proportion of cows identified as lame during the 6 -wk period post intervention was evaluated using the FREQ procedure of SAS with CHISQ option in the TABLES statement. Milk yield data were analyzed using the MIXED procedure and the Kenward-Roger denominator degrees of freedom adjustment. The model included the fixed effect of treatment, week post-treatment application, and their 2 -way interaction. Week was analyzed as a repeated measure with cow-within-treatment as the subject of the repeated statement. An unstructured covariance structure was used because it provided the best fit based on the Akaike information criterion. The 1-wk average milk yield measured before treatment application was included in the model as a covariate. Residuals of the final model were evaluated for normality and homoscedasticity. Least squares means (LSM) and standard errors (SE) are reported unless otherwise specified. Significance was declared at $P<0.05$ and tendency was declared at $0.05 \leq P<0.10$.

\section{RESULTS}

In herd $\mathrm{A}(\mathrm{n}=2,374)$, the proportion of lame cows was $7.9 \%$ (LS 3, $\mathrm{n}=187), 1.4 \%(\operatorname{LS~} 4, \mathrm{n}=32)$, and $0.0 \%(\operatorname{LS~} 5, \mathrm{n}=1)$, whereas $67.4 \%(\operatorname{LS~} 1, \mathrm{n}=1,599)$ and $23.4 \%$ (LS 2, $\mathrm{n}=555$ ) of cows were classified as sound. In herd B $(\mathrm{n}=2,800)$, only cows with $\mathrm{LS} \geq 3$ were recorded; $10.1 \%$ (LS 3, $\mathrm{n}=282$ ), $1.3 \%$ (LS 4, n $=37)$ and $0.4 \%(\mathrm{LS} 5, \mathrm{n}=11)$. Cows' characteristics measured before treatment assignment are presented in Table 1. Before enrollment, no significant differences were observed between the 2 groups on any of the measured variables, except for cows randomized to HTI in herd B that tended to have a lower DIM average.

\section{Locomotion Score Probability}

Overall, no significant treatment effect was observed on predicted locomotion score probability in herd A $(P$ $=0.554)$ or herd $\mathrm{B}(P=0.606$; Figure 1$)$. Time was significant for both herds $(P<0.001)$. Lameness predicted probability of LS $\geq 3$ decreased over time in herd B from 0.50 at 2 wk post-intervention to 0.23 and 0.27 at 4 and 6 wk post-intervention respectively. However, in herd $\mathrm{A}$, lameness predicted probability was 0.56 at $2 \mathrm{wk}$ post-intervention, decreasing to 0.44 at $4 \mathrm{wk}$, and increasing again to 0.75 at $6 \mathrm{wk}$ post-intervention.

A tendency for a treatment by time interaction was observed in herd $\mathrm{A}(P=0.077)$ but not in herd $\mathrm{B}(P=$

Table 1. Description (mean) of cows enrolled in the study assigned to control group or therapeutic trimming (hoof trimmer intervention, HTI)

\begin{tabular}{lcrcc}
\hline Item & Control & HTI & SEM & $P$-value \\
\hline Herd A & & & & \\
Cows, no. & 66 & 73 & - & - \\
DIM & 138.0 & 163.1 & 10.7 & 0.10 \\
Days pregnant & 36.1 & 40.8 & 7.0 & 0.64 \\
Milk yield at $-1 \mathrm{wk}, \mathrm{kg} / \mathrm{d}$ & 44.6 & 43.6 & 1.1 & 0.54 \\
Herd B & & & & \\
Cows, no. & 84 & 75 & - & - \\
DIM & 174.1 & 146.3 & 9.9 & 0.06 \\
Days pregnant & 49.3 & 36.7 & 6.6 & 0.18 \\
Milk yield at $-1 \mathrm{wk}, \mathrm{kg} / \mathrm{d}$ & 46.5 & 48.1 & 1.2 & 0.39 \\
\hline
\end{tabular}




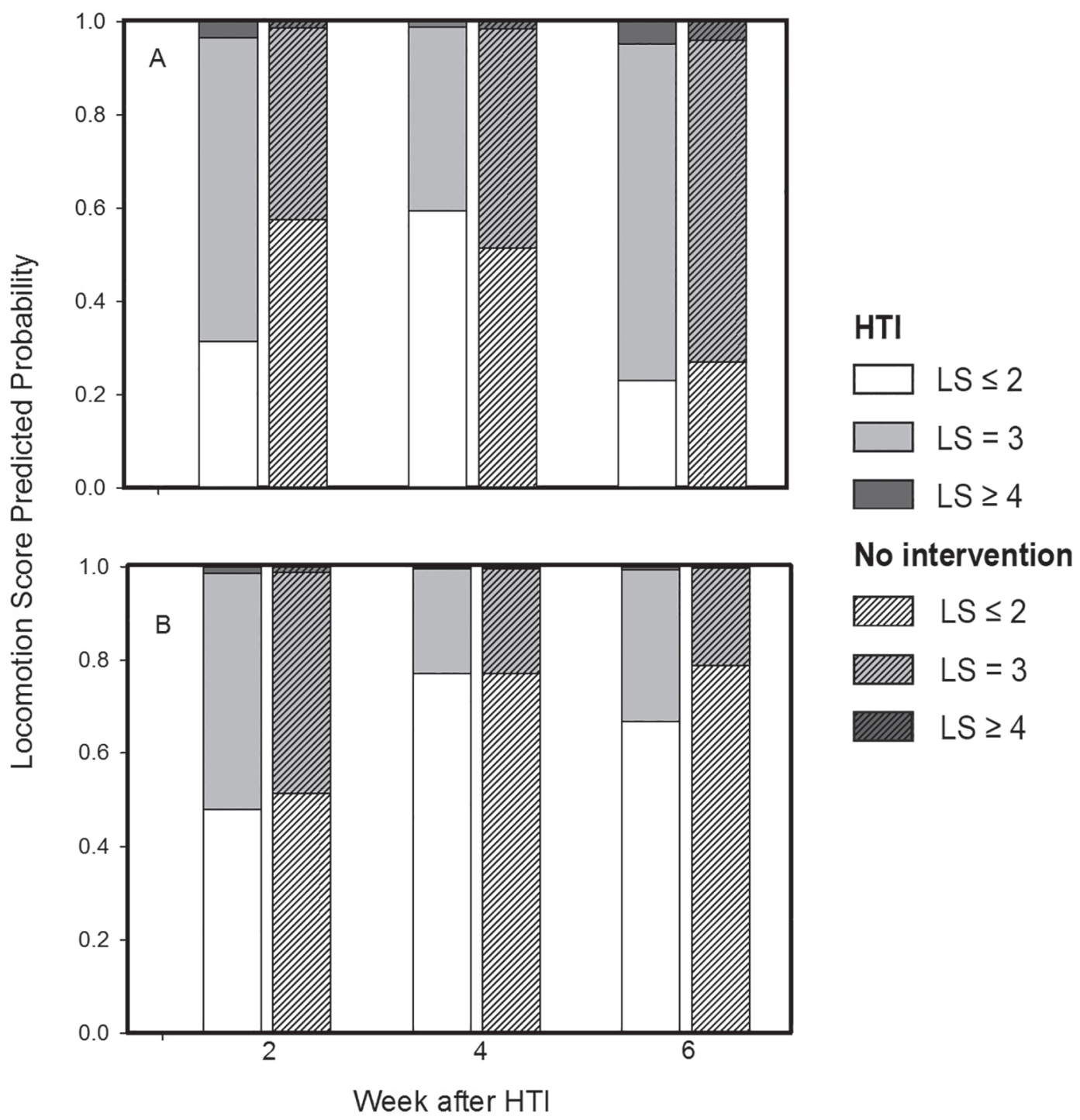

Figure 1. Locomotion score (LS) predictive probability for hoof trimmer intervention (HTI; $\mathrm{n}=137$ ) and no intervention (control) groups for herd A (panel A; $\mathrm{n}=137$ ) and herd B (panel B; $\mathrm{n}=159$ ). At enrollment, all cows were LS = 3. No significant treatment effect was observed in herd A $(P=0.554)$ or herd $\mathrm{B}(P=0.606)$. Time was significant for both herds $\mathrm{A}$ and $\mathrm{B}(P<0.001)$. The HTI resulted in a tendency for a treatment by time interaction in herd $\mathrm{A}(P=0.077)$ but not in herd $\mathrm{B}(P=0.598)$.

0.598). In herd A, lameness predicted probability of LS $\geq 3$ at 2 wk post-intervention was higher (mean; $95 \%$ CI) for cows on HTI $(0.65 ; 0.44-0.82)$ than on CON (0.41; 0.23-0.62), but no differences were observed at 4 wk between HTI $(0.39 ; 0.22-0.59)$ and CON $(0.47$; $0.28-0.67)$ or at 6 wk between HTI $(0.72 ; 0.52-0.86)$ and $\operatorname{CON}(0.69 ; 0.48-0.84)$.

\section{Hoof Lesion Assessment}

Lesion types by herd are shown in Table 2. During intervention, no lesions were detected in $45.2 \%$ of cows in herd $\mathrm{A}$ and $37.4 \%$ of cows in herd $\mathrm{B}$, whereas thin soles were observed in $4.1 \%$ of cows in herd $\mathrm{A}$ and $13.3 \%$ of cows in herd B. Overall, the most prevalent lesions were sole hemorrhages $(28.4 \%)$ and thin soles $(8.8 \%)$, followed by vertical horn fissure $(6.8 \%)$, white line disease $(4.1 \%)$, and digital dermatitis $(3.4 \%)$. Other conditions detected were heel horn erosions (2.7\%), sole ulcer $(2.0 \%)$, interdigital hyperplasia $(2.0 \%)$, and interdigital phlegmon $(0.7 \%)$. Most of those lesions $(82.7 \%)$ were classified with a severity of mild (score 1 of 3 ). Only cows with sole ulcer were fitted with a block: 3 cows in herd $\mathrm{A}$ and 2 cows in herd $\mathrm{B}$. 
During the 6 wk post-intervention, similar $(P=$ 0.523 ) numbers of lame cows were identified in both treatment groups: $\mathrm{CON}$ (herd $\mathrm{A}=8$, herd $\mathrm{B}=5$ ) and HTI (herd $\mathrm{A}=6$, herd $\mathrm{B}=4$ ). Claws of HTI lame cows presented white line disease $(\mathrm{n}=4)$, sole hemorrhage $(\mathrm{n}=3)$, no lesion $(\mathrm{n}=2)$, or sole ulcer $(\mathrm{n}=1)$, whereas claws of CON cows had sole ulcer $(\mathrm{n}=5)$, white line disease $(\mathrm{n}=3)$, fissure $(\mathrm{n}=3)$, sole hemorrhage $(\mathrm{n}=$ $1)$, and digital dermatitis $(n=1)$. Six of the 10 HTI cows identified as lame differed in their diagnosis at intervention (no lesion, sole hemorrhage, or white line disease) from the second diagnosis (sole hemorrhage, white line disease, or sole ulcer). Over half $(52.2 \%)$ of the cows identified as lame were detected by wk 2 after intervention.

\section{Milk Yield}

In herd $\mathrm{B}$, we detected a tendency $(P=0.087)$ toward a decreased milk yield (LSM; 95\% CI) for cows assigned to HTI $(43.7 \mathrm{~kg} / \mathrm{d}$; 42.6 to $45.0 \mathrm{~kg} / \mathrm{d})$ relative to $\mathrm{CON}(45.2 \mathrm{~kg} / \mathrm{d} ; 44.1$ to $46.4 \mathrm{~kg} / \mathrm{d})$. However, in herd $\mathrm{A}$, similar $(P=0.890)$ milk yields were observed for HTI $(42.3 \mathrm{~kg} / \mathrm{d}$; 40.8 to $43.8 \mathrm{~kg} / \mathrm{d})$ and CON $(42.0$ $\mathrm{kg} / \mathrm{d} ; 40.5$ to $43.5 \mathrm{~kg} / \mathrm{d}$ ) cows. Time was significant in both herds $(P<0.001)$, with milk yield decreasing over time. Overall, no significant treatment by time interaction was observed in herd A $(P=0.892)$ or herd $\mathrm{B}(P$ $=0.228$; Figure 2).

\section{DISCUSSION}

Hoof trimmer intervention in moderately lame cows has been proposed as a strategy to mitigate the negative consequences of lameness. However, very few studies have evaluated this hypothesis. Our study examined the effect of hoof trimmer intervention of moderately lame cows on gait and milk yield on 2 Holstein dairy farms. Based on the claw lesion observed, cows on HTI were treated with trimming alone or combined with a block on the sound claw and topical antibiotic therapy. In our study, no information was obtained on lameness onset; however, cows with therapeutic trimming records up to 2 mo before intervention were not included in the study. This was expected to reduce the enrollment of cows that were chronically lame or in a recovery phase. The proportion of cows with LS $\geq 3$ was $9.3 \%$ in herd A and $11.4 \%$ in herd B. Both herds benchmarked among the lowest 25th percentile for California (von Keyserlingk et al., 2012). The low proportion of lame cows reflects the good management practices implemented at the study dairies, including regular foot bath use, functional trimming at dry-off, paved walkways with rubber mats, cooling of cows, and maintaining wellbedded stalls.

Based on prior studies that suggested an improvement of cows' gait after early lameness treatment (Leach et al., 2012; Groenevelt et al., 2014; Thomas et al., 2015), we expected a positive effect of HTI on lameness progression and milk yield. However, the predicted

Table 2. Description of claw lesions observed on 148 cows assigned to hoof trimmer intervention (HTI) at study onset $(\mathrm{d} 0)^{1}$

\begin{tabular}{|c|c|c|c|c|c|}
\hline \multirow[b]{2}{*}{ Lesion type } & \multicolumn{3}{|c|}{ HTI (d 0) } & \multicolumn{2}{|c|}{ New cases } \\
\hline & $\begin{array}{l}\text { Herd } \mathrm{A}^{2} \\
(\mathrm{n}=73)\end{array}$ & $\begin{array}{l}\text { Herd } B^{3} \\
(\mathrm{n}=75)\end{array}$ & $\begin{array}{c}\text { Total } \\
(\mathrm{n}=148)\end{array}$ & Control & Treatment \\
\hline Total, no. & 73 & 75 & 148 & 13 & 10 \\
\hline No lesion, $\%$ & 45.2 & 37.4 & 41.1 & - & 20.0 \\
\hline Sole hemorrhage, $\%$ & 23.3 & 33.3 & 28.4 & 15.4 & 20.0 \\
\hline Thin sole, \% & 4.1 & 13.3 & 8.8 & - & - \\
\hline Vertical horn fissure, $\%$ & 9.6 & 4.0 & 6.8 & 23.1 & - \\
\hline White line disease, $\%$ & 6.9 & 1.3 & 4.0 & 23.1 & 40.0 \\
\hline Digital dermatitis, \% & 2.7 & 4.0 & 3.4 & 7.7 & - \\
\hline Heel horn erosion, \% & 2.7 & 2.7 & 2.7 & 15.4 & - \\
\hline Sole ulcer, $\%$ & 1.4 & 2.7 & 2.0 & 15.4 & 20.0 \\
\hline Interdigital hyperplasia, \% & 4.1 & - & 2.0 & - & - \\
\hline Interdigital phlegmon, $\%$ & - & 1.3 & 0.7 & - & - \\
\hline
\end{tabular}

${ }^{1}$ Lesions observed on lame cows selected by farmers during 6 wk after treatment (new cases) in control and HTI groups.

${ }^{2}$ All lesions were mild except for 8 moderate lesions ( 3 interdigital hyperplasia, 2 heel horn erosion, 2 white line disease, 1 sole hemorrhage, 1 sole ulcer), and 2 severe lesions (white line disease).

${ }^{3}$ All lesions were mild except for 2 moderate lesions (1 sole ulcer, 1 digital dermatitis) and 1 severe lesion (interdigital phlegmon). 


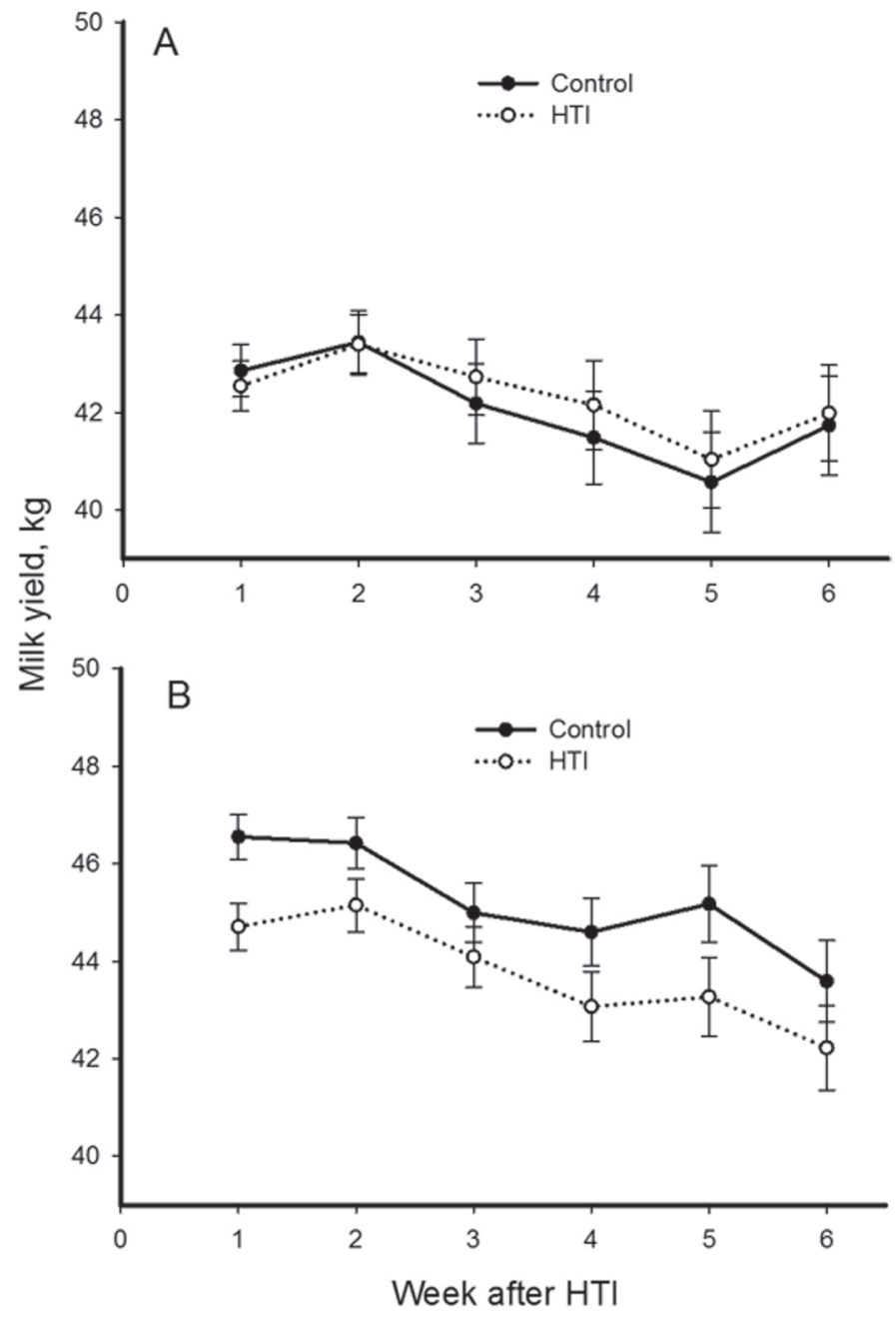

Figure 2. Weekly milk yield (LSM $\pm \mathrm{SE}$ ) for the control (no intervention) and hoof trimmer intervention (HTI) groups for herd A (panel A; $\mathrm{n}=139$ ) and herd B (panel B; $\mathrm{n}=159)$, respectively. All cows enrolled were initially locomotion score $=3$. No significant treatment by time interaction was observed for herd A $(P=0.892)$ or herd $\mathrm{B}(P=0.228)$. A tendency for a treatment effect was observed on herd B $(P=0.087)$ but not herd A $(P=0.890)$.

probability of LS $\geq 3$ in herd A at 2 wk post-intervention suggested that HTI could delay lameness recovery. Although the effect size in herd A was relevant at $2 \mathrm{wk}$ post-intervention (HTI: 0.65; CON: 0.41), it was trivial at 6 wk (HTI: 0.72; CON: 0.69). Studies have questioned the efficacy of current hoof-trimming techniques based on claw weight-bearing distribution (van der Tol et al., 2004) and measurements of dissected claws (Nuss and Paulus, 2006; Archer et al., 2015). More recently, researchers have shown that functional hoof trimming can have detrimental and long-term effects on gait (Van Hertem et al., 2014; Mahendran et al., 2017). Similarly, Chapinal et al. (2010) observed an increase in lying time and a decrease of walking speed that lasted several weeks after hoof trimming.

In our study, milk yield in both herds decreased over time. This is probably explained by average daily temperatures rising due to seasonal changes as well as an increase in cows' DIM. Hoof trimmer intervention tended to decrease milk yield by $1.5 \mathrm{~kg} / \mathrm{d}$ in herd B. However, in herd A, the magnitude of the effect size was negligible and not significant, with cows on HTI producing $0.3 \mathrm{~kg} / \mathrm{d}$ more than cows in the CON group. It is possible that the milk yield reduction associated with lameness occurred before hoof trimmer intervention and cows were never able to recover production after intervention. Studies evaluating early treatment of lame cows found no clear effect on milk yield (Leach et al., 2012). However, in a study conducted on a single dairy in Germany with 144 lactating cows, early treatment of lame cows resulted in a tendency toward higher milk yield at 100 DIM (Gundelach et al., 2013).

On intervention day, cows in herd A were away from their lactating pen for up to $8 \mathrm{~h}$, whereas cows in herd $\mathrm{B}$ were absent for less than $1.5 \mathrm{~h}$. Temporary deprivation of lying and feeding could result in a reduction of milk yield (Cooper et al., 2008). However, it was in herd B that HTI resulted in a tendency for reduced milk yield at wk 1. Another possible explanation for this finding is that HTI could have resulted in an undesirable reduction of sole thickness (Nuss and Paulus, 2006). At intervention, thin soles were observed more often in herd B than herd A. In herd B, cows had to walk to the milking parlor 3 times a day on floor surfaces with an added degree of abrasiveness from sand spilled out of stalls. The presence of thin soles has been associated with an increase in cows' susceptibility to hoof lesions or hoof pain and has been reported to affect milk yield (van Amstel et al., 2002, 2004). Moreover, in our study, lesion-specific treatment was dictated by current best management protocols. However, peer-reviewed, controlled research studies are needed to define the best treatment approach, especially for noninfectious claw lesions (Potterton et al., 2012).

The time from lameness onset to treatment may also have played a role in the treatment effects we observed. We excluded from our study cows with hoof trimming records during the 2 mo before enrollment, but we did not know the time of lameness onset in our study cows. In a recent study of the treatment of newly lame cows, regardless of lesion type with therapeutic trimming, a block and NSAIDs increased the proportion of sound cows compared with hoof trimming alone or combined with either a block or NSAID treatment (Thomas et al., 2015); however, no differences were detected in the proportion of nonlame cows. The positive treatment 
effects observed in newly lame cows were not detected when treatment was postponed for over 2 wk (Thomas et al., 2016). In our study, delay to treatment was probably even longer than $2 \mathrm{wk}$, and blocks were only applied to 5 cows.

Another factor that may explain our finding is the limited number of cows that had severe lesions (5.4\%). This observation was not expected because Bicalho et al. (2007) reported 55.5 and $29.6 \%$ of lame cows had painful lesions in moderately lame cows housed in 2 northeastern US herds. Similarly, Thomsen et al. (2012) observed that $55 \%$ (LS 3) and 35\% (LS 4) of cows had no visible claw lesions. The overall lack of claw lesions on cows exhibiting gait and postures indicative of moderate lameness has several possible explanations. The pain associated with a damaged corium can result in gait abnormalities even weeks before claw lesions can be detected (Bicalho et al., 2007; Thomsen et al., 2012). Therefore, cows might have had lesions that were not detected at the time of the intervention. Moreover, postures such as arched back reflect the animal's pain, which could have been caused by something other than lameness, such as liver abscess, reticuloperitonitis, metritis, or other conditions (Van Nuffel et al., 2015). Gait and postural anomalies could also be caused by musculo-skeletal lesions after falling down, bumping on stalls, hitting claws on steps, or other injuries. Differentiating between claw and upper limb lesions can be challenging and may require a diagnostic approach that is not feasible under farm conditions (Shearer et al., 2012). Although locomotion scoring systems are the current industry standard for claw lesion detection, they have been criticized for their subjective nature and have varying reliability and validity. They are highly affected by cow conformation, udder fill, flooring surface, and the ability of cows to mask signs of pain in the presence of an observer (Flower and Weary, 2009; Van Nuffel et al., 2015). In an earlier study designed to assess the association between postural and gait abnormalities observed at stanchions and milking parlor with lameness, and using LS $\geq 3$ as the reference method, $40 \%$ (10 out of 25 ) of moderately lame cows had no visible claw lesions (García-Muñoz et al., 2016). Thus, as shown in our study, selecting moderately lame cows for HTI based on a single LS evaluation might not be the most effective method to identify cows with claw lesions amenable to therapy.

\section{CONCLUSIONS}

We found that on 2 large California dairies, hoof trimmer intervention in moderately lame cows tended to have negative effects on gait (herd A) and milk yield (herd B). The uncertainty of lameness onset relative to intervention and the trimming technique used may have influenced results. Moreover, in our study, based on industry standard treatment protocols, a very limited number of moderately lame cows presented claw lesions that required immediate therapeutic trimming, block placement, or antibiotics. Thus, therapeutic hoof trimming may not always be the most effective treatment for moderately lame cows because causes other than claw lesions may explain abnormal gait. Future research should evaluate whether HTI would be an effective management strategy on dairies where moderate lameness etiology differs from our observations. Moving moderately lame cows to pens closer to the milking parlor, housing lame cows on dirt lots, administration of NSAIDs, or using thin therapeutic blocks might be alternative strategies to treat moderate lameness that should also be evaluated.

\section{ACKNOWLEDGMENTS}

This work was supported by the USDA National Institute of Food and Agriculture (Washington, DC; CFAH Animal Health under project 1002607), Zinpro Corporation (Eden Prairie, MN), and Nutrius LLC (Kingsburg, CA). The authors appreciate the collaboration of both participant dairies, Van Beek Bros and Dairyland (both in Tipton, Tulare County, CA), in allowing us to use their facilities, cows, and records. We sincerely value DeHaan hoof trimming services for their support and assistance during the study. Special appreciation is extended to Alfonso Lago (Dairy Experts Inc.), Arturo Gómez (Zinpro Corp.), and Luis Rodríguez (Zinpro Corp.) for their input on the experimental design and to Yolanda Trillo (Veterinary Medicine Teaching and Research Center) for her assistance with record-keeping.

\section{REFERENCES}

Akin, I., and N. Silva-del-Rio. 2013. Relationship between locomotion score and milk yield and composition in Holstein dairy cows. Pages 85-87 in Proc. 17th Int. Symp. and 9th Int. Conf. on Lameness in Ruminants. B. Whay and J. Hockenhull, ed. University of Bristol, Bristol, UK

Archer, S. C., M. J. Green, and J. N. Huxley. 2010. Association between milk yield and serial locomotion score assessments in UK dairy cows. J. Dairy Sci. 93:4045-4053. https://doi.org/10.3168/ jds.2010-3062.

Archer, S. C., R. Newsome, H. Dibble, C. J. Sturrock, M. G. G. Chagunda, C. S. Mason, and N. Huxley. 2015. Claw length recommendations for dairy cow foot trimming. Vet. Rec. 177:222-227. https://doi.org/10.1136/vr.103197.

Barker, Z. E., K. A. Leach, H. R. Whay, N. J. Bell, and D. C. J. Main. 2010. Assessment of lameness prevalence and associated risk factors in dairy herds in England and Wales. J. Dairy Sci. 93:932-941. https://doi.org/10.3168/jds.2009-2309. 
Bicalho, R. C., S. H. Cheong, G. Cramer, and C. L. Guard. 2007. Association between a visual and an automated locomotion score in lactating Holstein cows. J. Dairy Sci. 90:3294-3300. https://doi .org/10.3168/jds.2007-0076.

Burgi, K., and N. B. Cook. 2006. A visual guide to scoring lesions of the claw using a modified abc lesion scoring system. Page 179 in Proc. 14th Int. Symp. Lameness in Ruminants, Colonia, Uruguay. Accessed Apr. 21, 2016. http://www.ivis.org/proceedings/ rumlameness $/ 2006 /$ posters.pdf?LA $=1$

Chapinal, N., A. M. Passillé, and J. Rushen. 2010. Correlated changes in behavioral indicators of lameness in dairy cows following hoof trimming. J. Dairy Sci. 93:5758-5763. https://doi.org/10.3168/jds .2010-3426.

Cooper, M. D., D. R. Arney, and C. J. C. Phillips. 2008. The effect of temporary deprivation of lying and feeding on the behavior and production of lactating dairy cows. Animal 2:275-283. https://doi .org/10.1017/S1751731107001164

Dyer, R. M., N. K. Neerchal, U. Tasch, Y. Wu, P. Dyer, and P. G. Rajkondawar. 2007. Objective determination of claw pain and its relationship to limb locomotion score in dairy cattle. J. Dairy Sci. 90:4592-4602. https://doi.org/10.3168/jds.2007-0006.

Espejo, L. A., M. I. Endres, and J. A. Salfer. 2006. Prevalence of lameness in high-producing Holstein cows housed in freestall barns in Minnesota. J. Dairy Sci. 89:3052-3058. https://doi.org/10.3168/ jds.S0022-0302(06)72579-6.

Flower, F. C., and D. M. Weary. 2009. Gait assessment in dairy cattle. Animal 3:87-95. https://doi.org/10.1017/S1751731108003194.

Garbarino, E. J., J. A. Hernandez, J. K. Shearer, C. A. Risco, and W. W. Thatcher. 2004. Effect of lameness on ovarian activity in postpartum Holstein cows. J. Dairy Sci. 87:4123-4131. https://doi .org/10.3168/jds.S0022-0302(04)73555-9.

García-Muñoz, A., G. Vidal, N. Singh, and N. Silva-del-Río. 2016. Evaluation of two methodologies for lameness detection in dairy cows based on postural and gait abnormalities observed during milking and while restrained at headlock stanchions. Prev. Vet. Med. 128:33-40. https://doi.org/10.1016/j.prevetmed.2016.04.005.

Gbur, E. E., W. W. Stroup, K. S. McCarter, S. Durham, L. J. Young, M. Christman, M. West, and M. Kramer. 2012. Analysis of Generalized Linear Mixed Models in the Agricultural and Natural Resources Sciences. American Society of Agronomy (ASA), Crop Science Society of America (CSSA), and Soil Science Society of America (SSSA), Madison, WI.

Groenevelt, M., D. C. J. Main, D. Tisdal, T. G. Knowles, and N. J. Bell. 2014. Measuring the response to therapeutic foot trimming in dairy cows with fortnightly lameness scoring. Vet. J. 201:283-288. https://doi.org/10.1016/j.tvjl.2014.05.017.

Gundelach, Y., T. Schulz, M. Feldmann, and M. Hoedemaker. 2013 Effects of increased vigilance for locomotion disorders on lameness and production in dairy cows. Animals (Basel) 3:951-961. https:// doi.org/10.3390/ani3030951.

Horseman, S. V., E. J. Roe, J. N. Huxley, N. J. Bell, C. S. Mason, and H. R. Whay. 2014. The use of in-depth interviews to understand the process of treating lame dairy cows from the farmers' perspective. Anim. Welf. 23:157-165. https://doi.org/10.7120/09627286 .23.2.157.

Huxley, J. N. 2013. Impact of lameness and claw lesions in cows on health and production. Livest. Sci. 156:64-70. https://doi.org/10 .1016/j.livsci.2013.06.012.

ICAR Working Group. 2015. ICAR Claw Health Atlas. ICAR Working Group on Functional Traits and International Claw Health Experts. Accessed Apr. 21, 2016. http://www.icar.org/Documents/ ICAR Claw Health Atlas.pdf.

Juarez, S. T., P. H. Robinson, E. J. DePeters, and E. O. Price. 2003. Impact of lameness on behavior and productivity of lactating Holstein cows. Appl. Anim. Behav. Sci. 83:1-14. https://doi.org/10 .1016/S0168-1591(03)00107-2.

Kofler, J., G. Pesenhofer, G. Landl, I. Sommerfeld-Stur, and C. Peham. 2013. Monitoring of dairy cow claw health status in 15 herds using the computerised documentation program Claw Manager and digital parameters. Tierarztl. Prax. Ausg. G Grosstiere Nutztiere 41:31-44.
Leach, K. A., D. A. Tisdall, N. J. Bell, D. C. J. Main, and L. E. Green. 2012. The effects of early treatment for hindlimb lameness in dairy cows on four commercial UK farms. Vet. J. 193:626-632. https:// doi.org/10.1016/j.tvjl.2012.06.043.

Littell, R. C., G. A. Milliken, W. W. Stroup, R. D. Wolfinger, and O. Schabenberger. 2006. SAS for Mixed Models. 2nd ed. SAS Institute Inc., Cary, NC.

Mahendran, S. A., J. N. Huxley, Y. M. Chang, M. Burnell, D. C. Barrett, H. R. Whay, T. Blackmore, C. S. Mason, and N. J. Bell. 2017. Randomised controlled trial to evaluate the effect of foot trimming before and after first calving on subsequent lameness episodes and productivity in dairy heifers. Vet. J. 220:105-110. https://doi.org/ 10.1016/j.tvjl.2017.01.011.

Nuss, K., and N. Paulus. 2006. Measurements of claw dimensions in cows before and after functional trimming: A post-mortem study. Vet. J. 172:284-292. https://doi.org/10.1016/j.tvjl.2005.04.031.

Pineda, M., I. Akin, and N. Silva-del-Rio. 2015. Survey of lame cow management practices on California dairies. Page 150 in Proc. 18th Int. Symp. Lameness in Ruminants, Valdivia, Chile. Accessed Apr. 21, 2016. http://www.ruminantia.it/wp-content/uploads/ 2016/06/INTERNATIONAL-SYMPOSIUM-ON-LAMENESS-IN -RUMINANT-2016.pdf.

Potterton, S. L., N. J. Bell, H. R. Whay, E. A. Berry, O. C. D. Atkinson, R. S. Dean, D. C. J. Main, and J. N. Huxley. 2012. A descriptive review of the peer and non-peer reviewed literature on the treatment and prevention of foot lameness in cattle published between 2000 and 2011. Vet. J. 193:612-616. https://doi.org/10 $.1016 / j . t v j 1.2012 .06 .040$.

Reader, J. D., M. J. Green, J. Kaler, S. A. Mason, and L. E. Green. 2011. Effect of mobility score on milk yield and activity in dairy cattle. J. Dairy Sci. 94:5045-5052. https://doi.org/10.3168/jds .2011-4415.

Shearer, J. K., M. L. Stock, S. R. Van Amstel, and J. F. Coetzee. 2013. Assessment and management of pain associated with lameness in cattle. Vet. Clin. North Am. Food Anim. Pract. 29:135-156. https://doi.org/10.1016/j.cvfa.2012.11.012.

Shearer, J. K., S. R. Van Amstel, and B. W. Broderse. 2012. Clinical diagnosis of foot and leg lameness in cattle. Vet. Clin. North Am. Food Anim. Pract. 28:535-556. https://doi.org/10.1016/j.cvfa .2012.07.003.

Sprecher, D. J., D. E. Hostetler, and J. B. Kaneene. 1997. A lameness scoring system that uses posture and gait to predict dairy cattle reproductive performance. Theriogenology 47:1179-1187.

Tadich, N., E. Flor, and L. Green. 2010. Associations between hoof lesions and locomotion score in 1098 unsound dairy cows. Vet. J. 184:60-65. https://doi.org/10.1016/j.tvjl.2009.01.005.

Thomas, H. J., G. G. Miguel-Pacheco, N. J. Bollard, S. C. Archer, N. J. Bell, C. Mason, O. J. Maxwell, J. G. Remnant, P. Sleeman, H. R. Whay, and J. N. Huxley. 2015. Evaluation of treatments for claw horn lesions in dairy cows in a randomized controlled trial. J. Dairy Sci. 98:4477-4486. https://doi.org/10.3168/jds.2014-8982.

Thomas, H. J., J. G. Remnant, N. J. Bollard, A. Burrows, H. R. Whay, N. J. Bell, C. Mason, and J. N. Huxley. 2016. Recovery of chronically lame dairy cows following treatment for claw horn lesions: A randomised controlled trial. Vet. Rec. 178:116. https://doi.org/10 $.1136 /$ vr.103394.

Thomsen, P. T., L. Munksgaard, and J. T. Sørensen. 2012. Locomotion scores and lying behavior are indicators of hoof lesions in dairy cows. Vet. J. 193:644-647. https://doi.org/10.1016/j.tvjl .2012.06.046

Toussaint-Raven, E. 1985. Cattle Footcare and Claw Trimming. Farming Press, Ipswich, UK.

van Amstel, S. R., F. L. Palin, J. K. Shearer, and B. F. Robinson. 2002. Anatomical measurement of sole thickness in cattle following application of two different trimming techniques. Bovine Pract. 36:136-140. https://doi.org/10.3168/jds.S0022-0302(04)73219-1.

van Amstel, S. R., F. L. Shearer, and F. L. Palin. 2004. Moisture content, thickness, and lesions of sole horn associated with thin soles in dairy cattle. J. Dairy Sci. 87:757-763. https://doi.org/10.3168/ jds.S0022-0302(04)73219-1. 
van der Tol, P. P., S. S. van der Beek, J. H. Metz, E. N. NoordhuizenStassen, W. Back, C. R. Braam, and W. A. Weijs. 2004. The effect of preventive trimming on weight bearing and force balance on the claws of dairy cattle. J. Dairy Sci. 87:1732-1738. https://doi.org/ 10.3168/jds.S0022-0302(04)73327-5.

Van Hertem, T., Y. Parmet, M. Steensels, E. Maltz, A. A. Schlageter-Tello, C. Lokhorst, C. E. B. Romanini, S. Viazzi, C. Bahr, D. Berckmans, and I. Halachmi. 2014. The effect of routine hoof trimming on locomotion score, ruminating time, activity, and milk yield of dairy cows. J. Dairy Sci. 97:4852-4863. https://doi.org/10 $.3168 /$ jds.2013-7576.

Van Nuffel, A., I. Zwertvaegher, L. Pluym, S. Van Weyenberg, V. M. Thorup, M. Pastell, B. Sonck, and W. Saeys. 2015. Lameness detection in dairy cows: Part 1 . How to distinguish between non-lame and lame cows based on differences in locomotion or behavior. Animals (Basel) 5:838-860. https://doi.org/10.3390/ani5030387. von Keyserlingk, M. A. G., A. Barrientos, K. Ito, E. Galo, and D. M. Weary. 2012. Benchmarking cow comfort on North American freestall dairies: Lameness, leg injuries, lying time, facility design, and management for high-producing Holstein dairy cows. J. Dairy Sci. 95:7399-7408. https://doi.org/10.3168/jds.2012-5807.

Washington State University. 2013. Training module: How to locomotion score dairy cows. CAHNRS Veterinary Medicine Extension. Accessed May 20, 2013. http://vetextension.wsu.edu/research -projects/lameness/training/.

Whay, H. R., and J. K. Shearer. 2017. The impact of lameness on welfare of the dairy cow. Vet. Clin. North Am. Food Anim. Pract. 33:153-164. https://doi.org/10.1016/j.cvfa.2017.02.008. In press.

Zinpro Corp. 2010. Locomotion score of dairy cattle. Zinpro Corp Eden Prairie, MN. Accessed May 2013. http://www.zinpro.com/ video-library/dairylocomotion-videos\#/videos/list. 